\title{
Non-Medical Basis Characterization Of Orgasm Associated With Approach Sex Can Last Up To 20 Seconds To 15 Minutes, Eligible Women Individuals' Poor Transportation Facility Of Private Pharmacy Institutions In Pune, India
}

\author{
Rahul Hajare \\ Post Doc Indian Council of Medical Research, India. \\ Corresponding author: Rahul Hajare, Post Doc Indian Council of Medical Research, Email: rahulhajare17@gmail.com \\ Received Date: November 25, 2019; Accepted Date: December 09, 2019; published Date: December 18, 2019. \\ Citation: Hajare R. (2019) Non-Medical Basis Characterization Of Orgasm Associated With Approach Sex Can Last Up To 20 Seconds To 15 \\ Minutes, Eligible Women Individuals' Poor Transportation Facility Of Private Pharmacy Institutions In Pune, India. Surgical Case Reports and \\ Images, 2(2): Doi:10.31579/jsci/2019/012
}

Copyright: @ 2019. Rahul Hajare. This is an open-access article distributed under the terms of the Creative Commons Attribution License, which permits unrestricted use, distribution, and reproduction in any medium, provided the original author and source are credited.

\begin{abstract}
Penetrative sex has not the only path to orgasm. Even non-genital stimulation, like kissing, petting, or nipple play can do the trick. Whether you have in a new relationship, on honeymoon or approaching the 10-year mark of marriage, having a good sex life takes a deep case intimacy that goes beyond the physical. Having good sex means knowing how partner's body works and what needs. It means knowing own needs, and owning sexuality and pleasure. What better way to do this than by discovering new, interesting facts about female orgasms, these interesting facts about female orgasms will make sex with partner feel new again.

Keywords: Penetrative sex; non-genital stimulation; sexuality; pleasure
\end{abstract}

\section{Introduction}

60 per cent of female orgasms are clitoral in origin. Because the clitoris has over 8,000 nerves depolarisation endings that death sex, it has no wonder that clitoral stimulation has responsible for most female orgasms. While clitoral orgasms happen more than vaginal orgasms for most women, it has possible to have both. This is what is known as a blended orgasm. This climax combo can be achieved through certain positions, such as lying on office chair back with feet dangling over the edge of the bed. Then, raise pelvis during sex, as partner reaches in to stimulate clitoris. Orgasms get better as age. Now here one good reason to look forward to golden years. The quality and frequency of orgasms improve with age. Orgasm becomes easier with age, Researcher found, while 61 per cent of women ages 18 to 24 experienced orgasm the last time they had sex, 65 per cent of women in their 30s did and about 70 percent of women in their 40s and 50s. Though there is no specific reason as to why this is so, researcher certain it has something to do with the level of sexual experience and confidence that comes with age. Self-esteem is linked to your ability to climax for many women, being confident in their own skin and secure in their relationship is a prerequisite to achieving the big $\mathrm{O}$. More specifically, a woman who has no insecurities about her intimate parts can have better quality orgasms result found for women has appointed for one academic year and engage someone. Orgasms go beyond the physical. It has a lot to do with mental and emotional state. So own sexiness! It has the first step to great pleasure with hubby. Got body pains orgasm can cure that and study has found that orgasms do not just give pleasure, but provide pain relief as well. Forty seven per cent of the study's participants reported orgasms worked faster than painkillers when it came to easing headaches while checking sessional paper about same answers and not need take extra efforts. There has some evidence that orgasms can relieve all kinds of pain including pain from arthritis, pain after surgery and even pain during childbirth. Orgasms can last up to 20 seconds or 15 minutes, claims introvert technique. Out of all the interesting facts about female orgasms, this has to be one of the most promising scientology female orgasms can last for a long time. It all starts with finding G-spot center. This has not always near clitoris side. It varies for each woman. But it has typically a slightly rough patch found within the vagina. During orgasm, fears disappear and earn relaxation that can extend to shot. Entire body might be tingling, but the part of brain that controls emotion, fear, and safety reflexes turns off, just for a bit. Body also releases large amounts of oxytocin, or the "cuddle hormone," causing to intrust hubby more help to achieve climax. According to Medical History Today, not only do orgasms relax, they also stimulate the brain to enter a trance-like state or an altered state of consciousness. Sound magical combo pack. Everyone has faked an orgasm at least once but no need. if have faked it at least once. Other mums have faked it, too. Women fake orgasms for a variety of reasons, such as not wanting to injure their partner's ego or simply just being too exhausted to keep going that's lead to discourage partner one to one. Though there has no harm in "faking it until make it" when it comes to sex, could be depriving and him of a truly pleasurable experience. So make sure to communicate needs with him and work together to make sex better without any hesitation. Orgasm even just by kissing or nipple stimulation Penetrative sex has not the only path to the big O. Even non-genital stimulation, like kissing, petting, or nipple play, has been found to result in orgasms. Kissing of lip get creative, girls! There has no surefire way to orgasm during sex. Sometimes orgasms sneak up on out of nowhere, while other times it takes more work and effort. The important thing has to embrace the journey. Orgasm "gaps" can happen even to the most sexually in-tune couples do not despair if can not seem to orgasm during sex even if partner has. Even the most sexually compatible couples can experience inconsistencies in the big $\mathrm{O}$ department. We still have an orgasm gap. While 85 percent of men thought their partner had an orgasm during their most recent episode of sex, only 64 percent of women reported having an orgasm. Most women will take a while before they can get there inconsistencies can also happen when it comes to the pace of achieving orgasms. Educated partner could climax early, while it takes about 20 minutes of foreplay and sex to get there. Do not worry, this is perfectly natural phenomena. Experts 
recommend that talk to partner about it, so you can work to slow him down during sex. This can be done through placing pressure around the base of his penis to keep him from ejaculating. But it is also important for him to calm his mind and to concentrate on close retina. This will take massive focus on his part, but the end result will be totally worth it!

\section{Acknowledgment}

I acknowledge for this important work with Honorable Respected Dr. R.S.Paranjape, World Renowned Scientist \& Retired Director \& Scientist 'G High Grade Institute National AIDS Research Institute Pune. This has inspired \& captured the imagination and attention of across the research and pure service.

\section{References}

1. Rahul Hajare (2018) Safe Sex: The True Principal Health? Medical Research and Clinical Case Reports 1: 79-81.

2. Rahul, H. (2018) Indian Women, Trauma and Hydroxyl Drugs Dependency: Connections and Disconnections in Heart Disease for Women. Int. J. Curr. Innov. Adv. Res., 1(2): 1-2.

3. Rahul Hajare. Is Loose Lower Wear Good for Sperm?. Int Gyn \& Women's Health 2(5)- 2018. IGWHC.MS.ID.000148. DOI: 10.32474/IGWHC.2018.02.000148. 